\title{
Incidence of sickle cell disease in an unselected cohort of neonates born in Berlin, Germany
}

\author{
Stephan Lobitz ${ }^{\star, 1,4}$, Claudia Frömmel ${ }^{2,4}$, Annemarie Brose $^{2}$, Jeannette Klein ${ }^{3}$ and Oliver Blankenstein ${ }^{3}$ \\ Sickle cell disease (SCD) does not occur in the indigenous German population. However, with the increasing numbers of \\ immigrants its prevalence is steadily rising. Nevertheless, robust epidemiological data is not available for Germany and, \\ consequently, the German newborn screening (NBS) program does not include SCD. Between 1 September 2011 and 30 \\ November 2012, an unselected cohort of 34084 Berlin newborns was tested for SCD. The results of 14 newborns were \\ consistent with SCD and 265 babies were identified as hemoglobin S (Hb S) carriers. These data indicate a $95 \%$ probability \\ that the incidence of SCD in Berlin is at least 2.5/10000. \\ European Journal of Human Genetics (2014) 22, 1051-1053; doi:10.1038/ejhg.2013.286; published online 8 January 2014
}

Keywords: sickle cell disease; newborn screening; HPLC; capillary electrophoresis

\section{INTRODUCTION}

SCD causes significant early morbidity and mortality. Many studies have shown that early detection and appropriate prophylactic measures help to prevent potentially fatal complications and many countries, including several Western and Central European nations have already introduced NBS programs for SCD or conducted regional pilot studies (see Table 2). ${ }^{1-9}$

To date, there is no comprehensive epidemiological data on SCD in Germany, although in major cities with large immigrant populations, the number of cases is considerable. 'Semi-epidemiological' information is available from the Ulm longitudinal study published in 2010. ${ }^{10}$ The authors reported on 100621 hemoglobin analyses performed in Germany's leading diagnostic facility from 1971 to 2007 as part of the diagnostic workup of anemic patients from all over the country. During these 37 years, Kohne et al. identified 3085 individuals with several types of SCD. With regard to NBS for SCD, a report on a targeted study including 306 neonates born to African mothers in Munich is the only literature available from Germany so far. ${ }^{11}$ However, such a preselective approach has several limitations, as it will miss all affected children with a non-African ethnic background and, ultimately, does not provide comprehensive epidemiological information.

\section{The German NBS program}

In Germany, NBS is offered to all parents. Participation is voluntary. Nevertheless, the estimated participation rate is close to $100 \% .{ }^{12}$ NBS is done from heel prick dried blood spots that are sampled between the 36th and 72nd hour of life. Very early preterm newborns are re-screened as soon as they have a corrected age of 32 weeks of gestation. The German NBS program comprises 14 conditions, the most prevalent of which is congenital hypothyroidism (1/3275). ${ }^{13}$ In addition, all newborns are screened for congenital auditory defects. Blood disorders are not included.

\begin{abstract}
Aims
This pilot study was conducted to determine for the first time the incidence of SCD in an unselected cohort of neonates born in Germany.

\section{MATERIALS AND METHODS}

Study design and population

The present study is a retrospective cross-sectional investigation of an unselected cohort of newborns. All children born in Berlin between 1 September 2011 and 30 November 2012 were considered eligible for this project provided they took part in the routine NBS program.
\end{abstract}

\section{Target conditions and screening procedure}

The primary target conditions of this study included SCD-S/S, SCD-S/C, SCD-S/D ${ }^{\text {Punjab }}$, SCD-S/E, SCD-S/Lepore, SCD-S/O ${ }^{\text {Arab }}, S C D-S / \beta$ thalassemia, $\mathrm{SCD}-\mathrm{S} / \delta \beta$ thalassemia and SCD-S/HPFH (hereditary persistence of fetal hemoglobin).

Samples were first analyzed in our routine NBS laboratory, stored at room temperature and forwarded to the study laboratory after $2-4$ months. A twotier screening procedure was used. High-performance liquid chromatography (HPLC) served as the first-line method. ${ }^{14,15}$ Specimens with HPLC profiles consistent with SCD, sickle cell trait (SCT), $\beta$ thalassemia or variant hemoglobins other than $\mathrm{Hb} \mathrm{S}$ were subsequently analyzed by capillary electrophoresis (CE) as a confirmatory method. ${ }^{16,17}$

HPLC analyses were performed on a VARIANT nbs Newborn Screening System (Bio-Rad Laboratories, Munich, Germany) using the VARIANT nbs Sickle Cell Program. Data acquisition, management and analysis were conducted with the GDM 3.0 software (Bio-Rad Laboratories, Munich, Germany). HPLC measurements, maintenance and calibration of the HPLC system were carried out according to the manufacturer's recommendations. All chromatograms were automatically analyzed and also visually inspected.

Capillary electrophoreses were performed on a Sebia CAPILLARYS 2 CE system (Sebia, Fulda, Germany). Data acquisition, management and analysis were conducted with the PHORESIS 6.51 software. The fully automated CE measuring procedure was carried out according to the manufacturer's recommendations. The protocol has recently been published elsewhere. ${ }^{16,17}$ The migration properties of certain hemoglobins in CE are different from

${ }^{1}$ Department of Pediatric Oncology/Hematology/BMT, Charité-Universitätsmedizin Berlin, Berlin, Germany; ${ }^{2}$ Labor Berlin GmbH, Berlin, Germany; ${ }^{3}$ Newborn Screening Laboratory, Charité-Universitätsmedizin Berlin, Berlin, Germany

${ }^{*}$ Correspondence: Dr S Lobitz, Department of Pediatric Oncology/Hematology/BMT, Charité—Universitätsmedizin Berlin, Augustenburger Platz 1, 13353 Berlin, Germany. Tel: +49 (0)30 450666407; Fax: +49 (0)30 450566946; E-mail: stephan.lobitz@charite.de

${ }^{4}$ These authors contributed equally to this work.

Received 27 May 2013; revised 4 November 2013; accepted 20 November 2013; published online 8 January 2014 
those in HPLC, which allows for separation of hemoglobin species that co-migrate in HPLC and vice versa. In addition, all electropherograms were visually inspected.

An excellent guide through methodology is available on the website of the UK NHS Sickle Cell and Thalassaemia Screening Programme (http://sct. screening.nhs.uk/).

\section{Statistics}

Statistics are based on the assumption of a Poisson distribution, which allows calculation of the probability of a given number of independent events occurring in a fixed interval of time provided the average number of events per interval is known. As the latter precondition was not fulfilled, hypothetical incidences of 1.5 , 2.0 and 2.5 cases of SCD per 10000 newborns were used instead.

\section{Ethics and consent}

The ethics committee of the Charite university hospital approved the study on 28 September 2011 (reference number EA2/088/11). The parents of all newborns investigated gave their written informed consent to re-analysis of blood in advance of sampling.

\section{Handling of results}

If both HPLC and CE analysis of a baby's blood were indicative of a significant hemoglobinopathy, the family was contacted and referred to our department of pediatric hematology, where the presumed diagnosis was confirmed from fresh blood sample by molecular genetic analysis. Telephone numbers and addresses were extracted from the routine NBS database. Carrier states were not reported as required by our local ethics committee.

\section{RESULTS AND DISCUSSION}

Patient recruitment

In the study period, 39249 children were born in Berlin. A total of 95 newborns did not take part in screening due to parental refusal (unpublished data from the only Berlin Newborn Screening Laboratory). Hence, 39154 dried blood spot cards were collected. Of these, 5070 samples $(12.94 \%)$ were excluded for various reasons (see Figure 1). Finally, 34084 of 39249 newborns (86.84\%) were enrolled.

\section{First-line results (HPLC)}

Altogether 34084 samples were screened by HPLC and results of 14 newborns (4.11/10 000) were consistent with SCD. In 10 cases, only hemoglobins $\mathrm{F}$ and $\mathrm{S}$ were detectable. Five different genotypes can explain this phenotype, with homozygosity for $\beta^{\mathrm{S}}$ globin being the most common. Compound heterozygosity for $\beta^{S}$ globin and $\beta^{\circ}$ thalassemia, $\delta \beta$ thalassemia or deletional HPFH, respectively, and some cases of SCD-S/ $\beta^{+}$thalassemia result in an FS pattern as well.

In four samples, hemoglobin patterns indicative of SCD-S/C were observed. One newborn had an FE pattern, which may indicate homozygosity for $\mathrm{Hb} \mathrm{E}$ as well as $\mathrm{Hb} \mathrm{E} / \beta$ thalassemia. In 265 samples (75.11/10000) the HPLC results were consistent with SCT. In addition, 71 variants in heterozygous states were picked up.

\section{Second-line results $(\mathrm{CE})$}

All 351 HPLC results that provided evidence of the presence of any target condition or any variant hemoglobin were confirmed by $\mathrm{CE}$. For detailed results, please refer to Table 1.

\section{Statistics}

Amongst the 34084 newborns included in the study, 14 cases of SCD were detected. Calculations based on the assumption of a Poisson distribution indicate that the probabilities of detecting at least 14 affected babies in our cohort are only $0.086,1.04$ or $5.225 \%$, assuming hypothetical incidences of $1.5 / 10000,2.0 / 10000$ or $2.5 / 10000$, respectively.
Table 1 Summary of all screening results

\begin{tabular}{lrc}
\hline Hemoglobin pattern & Number of newborns & Incidence (\%) \\
\hline FA & 33733 & $98.970 \%$ \\
FS & 10 & $0.029 \%$ \\
FSC & 4 & $0.012 \%$ \\
FE & 1 & $0.003 \%$ \\
FAS & 265 & $0.777 \%$ \\
FAE & 27 & $0.079 \%$ \\
FAC & 23 & $0.067 \%$ \\
FAD & 11 & $0.032 \%$ \\
FAX & 10 & $0.029 \%$ \\
Total & 34084 & $100 \%$ \\
\hline
\end{tabular}

Fourteen newborns were identified with hemoglobin patterns consistent with SCD (10 FS, 4 FSC). In one baby we found an FE pattern consistent with $\mathrm{Hb} E / \beta$ thalassemia or $\mathrm{Hb} \mathrm{E}$ homozygosity. The most common heterozygous state was SCT, followed by $\mathrm{Hb} \mathrm{E}, \mathrm{Hb} C$ and $\mathrm{Hb}$ $\mathrm{D}$ heterozygosity, respectively. In addition, we found 10 babies with variants other than $\mathrm{Hb} \mathrm{S}$, $\mathrm{Hb} \mathrm{E}, \mathrm{HbC}$ and $\mathrm{Hb}$ D in heterozygous states (FAX).

Table 2 Overview of published studies on NBS for SCD from Europe

\begin{tabular}{lcrrrrr}
\hline Study & & Newborns & & & SCT/SCD & \\
location & Approach & screened & SCD & SCT & ratio & Reference \\
\hline Amsterdam & Targeted & 1016 & 4 & 19 & $(4.75)$ & 19 \\
Brussels & Universal & 179788 & 113 & 2745 & 24.29 & 20 \\
England & Universal & 1069173 & & 10000 & $\approx 15$ & 21 \\
& & 1198614 & 651 & & & \\
Ferrara & Targeted & 1992 & 0 & 24 & $n / a$ & 22 \\
France & Targeted & 2622870 & 3890 & 64269 & $(16.52)$ & 23 \\
Liège & Universal & 11995 & 10 & 184 & 18.4 & 20 \\
Madrid & Universal & 190238 & 29 & 732 & 25.24 & 24 \\
Netherlands & Universal & 21969 & 3 & 83 & 27.67 & 15,25 \\
Nice & Targeted & 19775 & 12 & 139 & $(11.58)$ & 26 \\
Paris & Targeted & 115480 & 250 & 6168 & $(24.67)$ & 27 \\
Spain & Universal/ & 226997 & 43 & $n / a$ & $n / a$ & 28 \\
& targeted & & & & & \\
Berlin & Universal & 34084 & 14 & 265 & 18.93 & Present \\
& & & & & & study
\end{tabular}

SCT-to-SCD ratios of targeted approaches are in brackets. Please note that there is overlap between some publications (eg Madrid and Spain). Respective references are available as online Supplementary Material.

\section{DISCUSSION}

In the period covered by our study, SCD was the most common condition detected by the Berlin NBS program, coming even before hypothyroidism (1/2435 vs 1/3275). Berlin thus fulfilled the criteria of a high-prevalence region according to the definition of the British NHS Sickle Cell \& Thalassaemia Programme often used as reference $(>1.5 / 10000)$. However, in Germany as in England, it can be assumed that there are considerable differences between urban and rural areas and possibly also between individual cities owing to different proportions of immigrants who, on account of their ethnic origin, are at a high risk of having children with SCD.

There is a striking discrepancy in Germany between the number of genetic carriers and those affected. Explaining this phenomenon is highly speculative. However, the German SCT-to-SCD ratio is in line with the data from other European studies (see Table 2).

Considerable hurdles are to be surmounted on the way to a national program for early detection of SCD through neonatal 
39,249 newborns

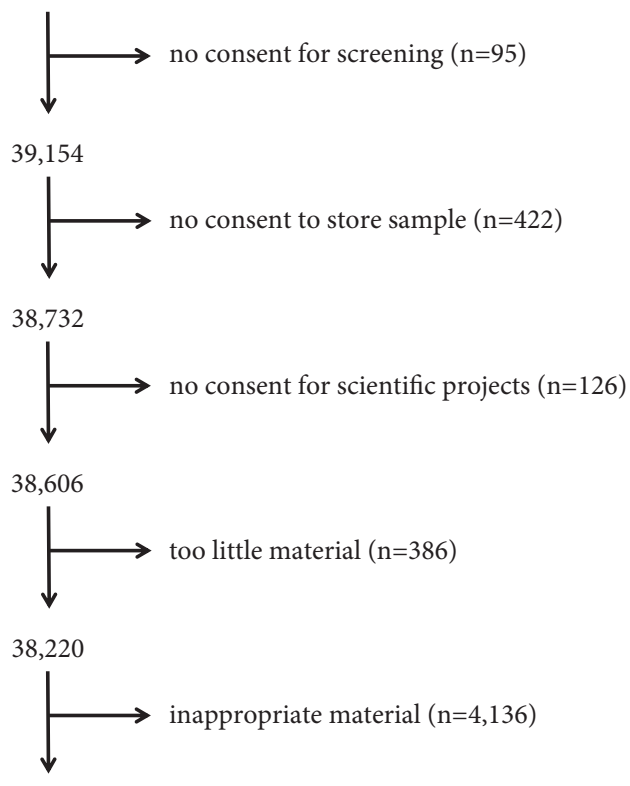

34,084 of 39,249 newborns (86.84\%) included in the study

Figure 1 Patient enrollment and reasons for drop-out. Most reasons are self-explanatory. 'Inappropriate material' refers virtually exclusively to samples with advanced degradation of hemoglobin resulting in the error-message 'low area' on the HPLC machine.

screening or, going even further, to a program for avoidance of the disease through identification and counseling of genetic carriers.

Factors specific to Germany include ethical concerns stemming from the country's history and the still young Genetic Diagnosis Act that guarantees internationally unique protection of the right not to know and the right to informational self-determination and, for example, prohibits informing parents of minors that their children are carriers of genes for autosomal-recessive diseases. ${ }^{18}$ This is of particular relevance in our specific context because it means that we are unable to use neonatal screening to identify high-risk families in which the $\beta^{S}$ gene is present but in which the disease has not yet occurred or been diagnosed (reproductive benefit), thus limiting the benefit of such a NBS program.

\section{CONCLUSIONS}

Our data indicate a $95 \%$ probability that the incidence of SCD in Berlin is at least $2.5 / 10000$. If future results corroborate this rate, a local NBS program for SCD should be initiated.

Data from other areas are now required to decide A) if Germany as a whole is in need of a national screening program for SCD and B) if yes, who, when and how to test. A comprehensive training of the staff involved is essential to ensure proper interpretation and utilization of the generated results.

\section{CONFLICT OF INTEREST}

SL, CF and OB received a research grant from Novartis Oncology GmbH (Nuremberg, Germany) to perform this study. In addition, Bio-Rad Laboratories GmbH (Munich, Germany) indirectly funded this project through a preferential price for HPLC consumables. The remaining authors declare no conflict of interest.

\section{ACKNOWLEDGEMENTS}

This work is part of SL's dissertation in the University College London 'Master of Science in Haemoglobinopathy' program. SL is deeply indebted to Dr Ratna Chatterjee, Dr Rekha Bajoria, the Thalassaemia International Federation (TIF) and 'KINDerLEBEN-Verein zur Förderung der Klinik für krebskranke Kinder e.V. Berlin'. We thank Novartis Oncology GmbH and Bio-Rad Laboratories $\mathrm{GmbH}$ who generously funded this project. Many thanks to all parents and patients who took part in this study.

1 Powars D, Overturf G, Weiss J, Lee S, Chan L: Pneumococcal septicemia in children with sickle cell anemia. Changing trend of survival. JAMA 1981; 245: 1839-1842.

2 Emond AM, Collis R, Darvill D, Higgs DR, Maude GH, Serjeant GR: Acute splenic sequestration in homozygous sickle cell disease: natural history and management. J Pediatr 1985; 107: 201-206.

3 Gaston $\mathrm{MH}$, Verter JI, Woods $\mathrm{G}$ et al: Prophylaxis with oral penicillin in children with sickle cell anemia. A randomized trial.. N Engl J Med 1986; 314: 1593-1599.

4 Serjeant GR, Serjeant BE: Management of sickle cell disease; lessons from the Jamaican Cohort Study. Blood Rev 1993; 7: 137-145.

5 Lee A, Thomas P, Cupidore L, Serjeant B, Serjeant G: Improved survival in homozygous sickle cell disease: lessons from a cohort study. BMJ 1995; 311: 1600-1602.

6 Adamkiewicz TV, Sarnaik S, Buchanan GR et al: Invasive pneumococcal infections in children with sickle cell disease in the era of penicillin prophylaxis, antibiotic resistance, and 23-valent pneumococcal polysaccharide vaccination. J Pediatr 2003; 143: 438-444.

7 Halasa NB, Shankar SM, Talbot TR et al: Incidence of invasive pneumococcal disease among individuals with sickle cell disease before and after the introduction of the pneumococcal conjugate vaccine. Clin Infect Dis 2007; 44: 1428-1433.

8 Adamkiewicz TV, Silk BJ, Howgate J et al: Effectiveness of the 7-valent pneumococcal conjugate vaccine in children with sickle cell disease in the first decade of life. Pediatrics 2008; 121: 562-569.

9 Grosse SD, Atrash HK, Odame I, Amendah D, Piel FB, Williams TN: The Jamaican historical experience of the impact of educational interventions on sickle cell disease child mortality. Am J Prev Med 2012; 42: e101-e103.

10 Kohne E, Kleihauer E: Hemoglobinopathies: a longitudinal study over four decades. Dtsch Arztebl Int 2010; 107: 65-71.

11 Dickerhoff R, Genzel-Boroviczeny O, Kohne E: Haemoglobinopathies and newborn haemoglobinopathy screening in Germany. J Clin Pathol 2009; 62: 34.

12 Harms E, Olgemoller B: Neonatal screening for metabolic and endocrine disorders. Dtsch Arztebl Int 2011; 108: 11-21, quiz 22.

13 Deutsche Gesellschaft für Neugeborenenscreening e.V.: National Screening Report Germany 2010 2012; http://www.screening-dgns.de/PDF/Screeningreport_2010_e.pdf

14 Eastman JW, Wong R, Liao CL, Morales DR: Automated HPLC screening of newborns for sickle cell anemia and other hemoglobinopathies. Clin Chem 1996; 42: 704-710.

15 Bouva MJ, Mohrmann K, Brinkman HB et al: Implementing neonatal screening for haemoglobinopathies in the Netherlands. J Med Screen 2010; 17: 58-65.

16 Renom G, Mereau C, Maboudou P, Perini JM: Potential of the Sebia Capillarys neonat fast automated system for neonatal screening of sickle cell disease. Clin Chem Lab Med 2009; 47: 1423-1432.

17 Murray C, Hall SK, Griffiths P: An evaluation of the Sebia capillarys Neonat Haemoglobin FAST system for routine newborn screening for sickle cell disease. Int J Lab Hematol 2011; 33: 533-539.

18 Enactment of the German Federal Parliament (Bundestag): Human Genetic Examination Act (Genetic Diagnosis Act-GenDG) 2009; https://www.eshg org/fileadmin/ www.eshg.org/documents/Europe/LegalWS/Germany_GenDG_Law_German_English.pdf 